\title{
Machine learning modeling for predicting hospital readmission following lumbar laminectomy
}

\author{
Saisanjana Kalagara, ScB, ${ }^{1}$ Adam E. M. Eltorai, PhD, ${ }^{1}$ Wesley M. Durand, ScB, ${ }^{1}$ \\ J. Mason DePasse, MD, ${ }^{1}$ and Alan H. Daniels, MD ${ }^{1,2}$ \\ 'Division of Spine Surgery and 2Department of Orthopaedic Surgery, Warren Alpert Medical School of Brown University, \\ Providence, Rhode Island
}

\begin{abstract}
OBJECTIVE Hospital readmission contributes substantial costs to the healthcare system. The purpose of this investigation was to create a predictive machine learning model to identify lumbar laminectomy patients at risk for postoperative hospital readmission.

METHODS Patients who had undergone a lumbar laminectomy procedure in the period from 2011 to 2014 were isolated from the American College of Surgeons National Surgical Quality Improvement Program (ACS NSQIP) database. Demographic characteristics and clinical factors, including complications, comorbidities, length of stay, age, and body mass index, were analyzed in relation to whether or not the patients had been readmitted to the hospital within 30 days after their procedure by utilizing independent-samples t-tests. Supervised gradient boosting machine learning was then used to create two models to predict readmission-one with all collected patient variables and one with only the variables known prior to hospital discharge.
\end{abstract}

RESULTS A total of 26,869 patients were evaluated, 5.59\% (1501 patients) of whom had an unplanned readmission to the hospital within 30 days of their procedure. Readmitted patients were older and had a greater number of complications and comorbidities, longer operative time, longer hospital stay, higher BMI, and higher work relative value unit (RVU) operation score $(p<0.01)$. They also had a worse health status prior to surgery $(p<0.01)$ and were more likely to be sent to a skilled discharge destination postoperatively $(p<0.01)$. The model with all patient variables accurately identified $49.6 \%$ of readmissions with an overall accuracy of $95.33 \%$ (area under the curve [AUC] $=0.8059$ ), with postdischarge complications and comorbidities as the most important predictors. The predictive model built with only clinical information known predischarge identified $40.5 \%$ of readmitted patients with an accuracy of $79.55 \%$ (AUC $=0.6901$ ), with discharge destination, comorbidities, and American Society of Anesthesiologists (ASA) classification as the most influential factors in identifying readmitted patients.

CONCLUSIONS In this study, the authors analyzed hospital readmissions following laminectomy and developed predictive models to identify readmitted patients with an accuracy of over $95 \%$ using all variables and over $79 \%$ when using only predischarge variables. Using only the variables available predischarge, the authors created a model capable of predicting $40 \%$ of the readmitted patients. This study provides data that will assist in the development of predictive models for readmission and the creation of interventions to prevent readmission in high-risk patients.

https://thejns.org/doi/abs/10.3171/2018.8.SPINE1869

KEYWORDS hospital readmission; spine surgery; machine learning; predictive model; lumbar; diagnostic technique

I N 2011 an estimated 3.3 million people in the US were readmitted to the hospital within 30 days of their discharge, leading to $\$ 41.3$ billion in potentially preventable healthcare expenditures. ${ }^{15}$ Patients over the age of 65 years and insured under Medicare had the highest readmission rates, making up 55.9\% of readmissions and accounting for $58.2 \%$ of readmission costs..$^{15}$ Additionally, readmitted patients had substantially reduced health-related quality of life measures, including both physical and psychosocial components. ${ }^{28,30}$

For spine surgery, reported 30-day readmission rates vary from $4.2 \%$ to $7.4 \% .^{8}$ A majority of these readmissions

ABBREVIATIONS ASA = American Society of Anesthesiologists; $\mathrm{AUC}=$ area under the receiver operating characteristic curve; $\mathrm{BMI}=$ body mass index; $\mathrm{GBM}=$ gradient boosting machine; LOS = length of stay; RVU = relative value unit; SMOTE = Synthetic Minority Oversampling Technique.

SUBMITTED March 14, 2018. ACCEPTED August 15, 2018.

INCLUDE WHEN CITING Published online December 7, 2018; DOI: 10.3171/2018.8.SPINE1869. 
are unplanned and attributable to postdischarge complications, whether medical or surgical. ${ }^{2}$ More than half of these cases require additional surgery and result in longer hospital stays. These effects can translate into substantially increased costs for the healthcare system. ${ }^{24,31}$

Because of its high rates and costs, readmission has gained substantial attention in recent years and is increasingly discussed as an indicator of a hospital's inpatient quality of care and discharge procedures.6,22,34 Therefore, in 2012 the Centers for Medicare and Medicaid Services (CMS) put into effect the Hospital Readmissions Reduction Program (HRRP), which incentivizes hospitals to bring down their readmission rates by reducing Medicare reimbursement payments to those with high rates. ${ }^{25}$ In 2017, of the approximately 3760 institutions participating in the program, 2597 of them, or $69 \%$, were penalized for high readmission numbers. ${ }^{3,40}$

Driven by a consumer push toward a higher quality of care and programs such as the HRRP, there has been increasing interest and research in reducing readmissions, especially those identified as preventable. ${ }^{4,19,27}$ By recent estimates, preventable readmissions make up as much as $20 \%$ of these cases and cost up to $\$ 17$ billion annually. ${ }^{37}$ There are also ongoing efforts to better understand and identify the factors that lead to readmission, which can lead to the development of more effective interventions. ${ }^{5,11,18}$ A recent investigation found that the most common causes for readmission after spine surgery included infection at the surgical site and pain. ${ }^{8}$

The objective of the present study was to analyze factors associated with 30-day hospital readmission following lumbar laminectomy and to create machine learning-based models to predict these readmissions. ${ }^{38} \mathrm{We}$ hypothesized that the factors most influential in forecasting readmission would be postoperative complications and preoperative patient health status, such as preexisting health conditions and dependency levels.

\section{Methods}

\section{Patient Selection}

Data were obtained from the American College of Surgeons National Surgical Quality Improvement Program (ACS NSQIP) database. This annually released data set collects de-identified demographic and clinical data from patient medical charts in hospitals across the country. Patients are also tracked for 30 days after their operation to collect additional information about complications. ${ }^{1}$ For this study, those who had undergone a laminectomy procedure (Current Procedural Terminology [CPT] codes 63001-63017, 63045-63048) ${ }^{29}$ between 2011 and 2014 were identified. The readmission status for each patient, whether or not they had been readmitted to the hospital in the 30 days after the operation, was obtained.

\section{Independent-Samples $\mathbf{t}$-Tests}

Independent-samples t-tests were performed to examine differences between those who had been readmitted and those who had not (statistical cutoff: $\mathrm{p}<0.05$ ). Fourteen variables describing patient and operation characteristics were examined: age, operation time, total hospital length of stay (LOS), postoperative LOS, body mass index (BMI), dependency, number of in-hospital complications, number of postdischarge complications, total number of complications, specific type of discharge destination postoperation, skilled discharge destination postoperation, American Society of Anesthesiologists (ASA) classification, work relative value units (RVUs) for the hospital stay, and number of comorbidities. Listwise deletion was utilized for missing data. Variables with more than $2.5 \%$ missing data were excluded in order to preserve statistical rigor.

Twenty-one common postsurgical complications and 36 comorbidities were evaluated for each patient (Table 1). ${ }^{21}$ Specific discharge destination is where the patients were discharged to, ranked by skill. A higher specific discharge destination score corresponds to a more skilled destination: home (score $=1$ ), facility that is home (score $=2$ ), unskilled facility that is not home (score $=3$ ), rehab $($ score $=4)$, skilled care (score $=5$ ), and separate acute care (score $=6$ ). The skilled destination variable was coded as either 0 to indicate a nonskilled destination or 1 to indicate a skilled destination. Lastly, a higher dependency score corresponds to a lower functional health status prior to surgery, from independent (score $=1$ ) to totally dependent (score $=3$ ). Data were analyzed using SPSS version 24 (IBM Corp.).

\section{Modeling Readmission With Supervised Machine Learning}

Machine learning algorithms to predict hospital readmission utilized $\mathrm{R}$ version 3.4.1 (R Foundation for Statistical Computing) and MATLAB version R2017a (MathWorks). The 14 characteristic variables were assigned as features in the model, and the readmission status was assigned as a binary outcome variable. Data were randomly partitioned into training $(85 \%)$ and testing $(15 \%)$ data sets. A Synthetic Minority Oversampling Technique (SMOTE) was subsequently applied to handle the class imbalance in the data set as only $5.59 \%$ of patients were readmitted. SMOTE is a widely used sampling-based algorithm that uses proportional oversampling and undersampling to create more balanced data and improve a model's predictive ability. ${ }^{10}$ Algorithms were performed both with and without SMOTE using the same testing data set for validation.

After the data set was prepared, the package rpart (https://cran.r-project.org/web/packages/rpart/rpart.pdf) was used on the training data to create decision trees, which are nonparametric supervised learning methods for classification problems. The decision tree was pruned by minimizing the cross-validated error to reduce complexity and prevent overfitting of the data. ${ }^{41}$ It was then used to understand how each feature impacted readmission and to identify the most important features out of the 14 .

Lastly, because readmission is a binary classification outcome, supervised gradient boosting machine (GBM) learning was used to create a prediction model. In this situation, gradient boosting is preferable to other types of ensemble machine learning, such as random forests. While the random forest technique consists of averaging all of the generated models, a GBM adds each new model to the others sequentially, iteratively improving the ensemble and more accurately estimating the outcome. ${ }^{26}$ Friedman's 
gradient boosting algorithm was used, where $L\left(y_{i}, f\right)$ is the loss function, $h\left(x_{i} ; a_{m}\right)$ is the base learner, and $\sigma_{m}$ is the optimized step size to add to the previous function $f_{m-1}(x):^{13,26}$

$$
\begin{aligned}
& \sigma_{m}=\arg \min _{\sigma} \sum_{i=1}^{N} L\left(y_{i}, f_{m-1}\left(x_{i}\right)+\sigma h\left(x_{i} ; a_{m}\right)\right)[\text { Eq. } 1]^{13} \\
& f_{m}(x)=f_{m-1}(x)+\sigma_{m} h\left(x ; a_{m}\right) \\
& {[\text { Eq. } 2]^{13}}
\end{aligned}
$$

For this study, a GBM with three repeats of a 10 -fold cross-validation technique was utilized, with each repeat consisting of 150 iterations to minimize the value of the loss function. Two different models were created: one with all the variables and one with only the predischarge variables. The algorithm was created based on the training data and then validated with the testing data set. The performance of each model in the test was evaluated by its accuracy, sensitivity, specificity, and area under the receiver operating characteristic curve (AUC). Further, relative importance values for each variable in the models were calculated, and partial dependency plots portraying the marginal effect of the variables on readmission were plotted (http://math.furman.edu/ dcs/courses/math47/R/ library/randomForest/html/partialPlot.html).

\section{Results}

In total, 26,869 patients were analyzed, 5.59\% (1501 patients) of whom had been readmitted within 30 days postoperatively. Readmitted patients and non-readmitted patients had statistically different values $(\mathrm{p}<0.001)$ for all 14 examined variables (Table 2 ). Those who had been readmitted were significantly older (64.668 vs 62.303, $\mathrm{p}<0.001)$ and had a significantly longer operation time (158.584 vs $140.349, \mathrm{p}<0.001)$, higher RVU procedure score (35.512 vs 31.646, $\mathrm{p}<0.001)$, longer total $(4.618$ vs $3.197, \mathrm{p}<0.001)$ and postoperation (3.861 vs 2.812 , p $<0.001$ ) hospital LOS, higher BMI (31.726 vs 30.957, p $<0.001$ ), greater number of complications (in-hospital: 0.170 vs $0.097, \mathrm{p}<0.001$; postdischarge: 0.684 vs 0.025 , $\mathrm{p}<0.001$; and total: 0.783 vs $0.117, \mathrm{p}<0.001$ ), and greater number of comorbidities (1.558 vs $1.212, \mathrm{p}<0.001)$.

Not all patients with recorded postdischarge complications were readmitted; $57.5 \%$ (331/576) of those with one, $55.7 \%(205 / 368)$ of those with two, and $82.0 \%$ (73/89) of those with three or more postdischarge complications were readmitted. Overall, 58.9\% (609/1033) of the patients with identified postdischarge surgical complications were readmitted. Further, readmitted patients also had greater dependency (lower functional status) prior to surgery (1.094 vs 1.036, $\mathrm{p}<0.001)$ and were ranked worse on the ASA classification scale (2.741 vs $2.507, \mathrm{p}<0.001)$. Lastly, patients who had been readmitted were more likely to be discharged to a skilled destination ( 0.301 vs 0.152 , p < 0.001) such as a skilled nursing home.

\section{Models Containing All Variables: Single Decision Tree}

The initial decision tree (Fig. 1) showed that three variables were predictive of readmission (in order of descending predictive power): postdischarge complications, any complications, and BMI. From this tree, three groups of patients were more likely to be readmitted than not. Fifty-

\begin{tabular}{|c|c|c|}
\hline No. & Complication & Comorbidity \\
\hline 1 & Superficial incisional SSI & Diabetes \\
\hline 2 & Deep incisional SSI & Smoking \\
\hline 3 & Organ/space SSI & High alcohol use \\
\hline 4 & Wound disruption & Ventilator dependent \\
\hline 5 & Pneumonia & History of severe COPD \\
\hline 6 & Unplanned intubation & Current pneumonia \\
\hline 7 & Pulmonary embolism & Ascites \\
\hline 8 & On ventilator for $>48 \mathrm{hrs}$ & Esophageal varices \\
\hline 9 & $\begin{array}{l}\text { Progressive renal insuf- } \\
\text { ficiency }\end{array}$ & $\begin{array}{l}\text { Congestive heart failure (in the } 30 \\
\text { days prior to surgery) }\end{array}$ \\
\hline 10 & Acute renal failure & $\begin{array}{l}\text { Myocardial infarction (in the } 6 \text { mos } \\
\text { prior to surgery) }\end{array}$ \\
\hline 11 & Urinary tract infection & $\begin{array}{l}\text { Previous percutaneous coronary } \\
\text { intervention }\end{array}$ \\
\hline 12 & Stroke/CVA & Previous cardiac surgery \\
\hline 13 & Coma (>24 hrs) & Angina (in the month prior to surgery) \\
\hline 14 & Peripheral nerve injury & Hypertension requiring medicine \\
\hline 15 & $\begin{array}{l}\text { Cardiac arrest requiring } \\
\text { CPR }\end{array}$ & $\begin{array}{l}\text { History of revascularization/amputa- } \\
\text { tion for peripheral vascular disease }\end{array}$ \\
\hline 16 & Myocardial infarction & Rest pain/gangrene \\
\hline 17 & Bleeding transfusion & Acute renal failure \\
\hline 18 & $\begin{array}{l}\text { Failure of graft, prosthe- } \\
\text { sis, or flap }\end{array}$ & Currently on dialysis \\
\hline 19 & Thrombophlebitis/DVT & Impaired sensorium \\
\hline 20 & Sepsis occurrence & In coma for $>24$ hrs \\
\hline 21 & Septic shock occurrence & Hemiplegia \\
\hline 22 & & History of transient ischemic attacks \\
\hline 23 & & $\begin{array}{l}\text { CVA or stroke w/ or w/o neurological } \\
\text { deficit }\end{array}$ \\
\hline 24 & & CNS tumor \\
\hline 25 & & Paraplegia \\
\hline 26 & & Quadriplegia \\
\hline 27 & & Disseminated cancer \\
\hline 28 & & Open wound infection prior to surgery \\
\hline 29 & & Steroid use for chronic condition \\
\hline 30 & & $\begin{array}{l}\text { Weight loss (>10\% loss in the } 6 \text { mos } \\
\text { prior to surgery) }\end{array}$ \\
\hline 31 & & Bleeding disorder \\
\hline 32 & & Preop transfusion of RBCs \\
\hline 33 & & $\begin{array}{l}\text { Chemotherapy (in the } 30 \text { days prior } \\
\text { to surgery) }\end{array}$ \\
\hline 34 & & $\begin{array}{l}\text { Radiotherapy (in the } 90 \text { days prior to } \\
\text { surgery) }\end{array}$ \\
\hline 35 & & Systemic sepsis \\
\hline 36 & & $\begin{array}{l}\text { Previous operation (in the } 30 \text { days } \\
\text { prior to surgery) }\end{array}$ \\
\hline
\end{tabular}

TABLE 1. List of examined complications and comorbidities*

CNS = central nervous system; COPD = chronic obstructive pulmonary disease; $\mathrm{CPR}=$ cardiopulmonary resuscitation; $\mathrm{CVA}=$ cerebrovascular accident; DVT = deep vein thrombosis; RBC = red blood cell; SSI = surgical site infection.

* Lawson et al., 2013. 
TABLE 2. Variable differences between readmitted and non-readmitted patients

\begin{tabular}{lcccccc}
\hline \multirow{2}{*}{ Variable } & $\begin{array}{c}\text { Readmitted } \\
\text { Patients }\end{array}$ & $\begin{array}{c}\text { Non-Readmitted } \\
\text { Patients }\end{array}$ & $\begin{array}{c}\text { Mean } \\
\text { Difference }\end{array}$ & $\mathrm{p}$ Value & Upper & Lower \\
\cline { 5 - 7 } Age & 64.668 & 62.303 & 2.365 & $<0.001$ & 3.072 & 1.659 \\
\hline $\mathrm{BMI}$ & 31.726 & 30.957 & 0.769 & $<0.001$ & 1.149 & 0.389 \\
\hline Dependency & 1.094 & 1.036 & 0.058 & $<0.001$ & 0.069 & 0.047 \\
\hline ASA classification & 2.741 & 2.507 & 0.234 & $<0.001$ & 0.267 & 0.202 \\
\hline Operation time & 158.584 & 140.349 & 18.235 & $<0.001$ & 22.802 & 13.669 \\
\hline RVU score & 35.512 & 31.646 & 3.866 & $<0.001$ & 5.044 & 2.688 \\
\hline Total hospital LOS & 4.618 & 3.197 & 1.421 & $<0.001$ & 1.745 & 1.097 \\
\hline Postoperation LOS & 3.861 & 2.812 & 1.048 & $<0.001$ & 1.412 & 0.684 \\
\hline Skilled discharge destination & 0.301 & 0.152 & 0.149 & $<0.001$ & 0.168 & 0.129 \\
\hline Specific discharge destination & 2.058 & 1.546 & 0.512 & $<0.001$ & 0.581 & 0.443 \\
\hline Comorbidities & 1.558 & 1.212 & 0.346 & $<0.001$ & 0.403 & 0.290 \\
\hline Total complications & 0.783 & 0.117 & 0.666 & $<0.001$ & 0.691 & 0.641 \\
\hline In-hospital complications & 0.170 & 0.097 & 0.073 & $<0.001$ & 0.093 & 0.052 \\
\hline Postdischarge complications & 0.684 & 0.025 & 0.659 & $<0.001$ & 0.675 & 0.642 \\
\hline
\end{tabular}

nine percent of the people with any postdischarge complication were readmitted. Seventy-seven percent of patients who had a postdischarge complication and at least two complications in total were readmitted. Fifty-eight percent of those with a postdischarge complication and a BMI > $25 \mathrm{~kg} / \mathrm{m}^{2}$ were readmitted.
Though only $3 \%$ of those without postdischarge complications were readmitted, they composed $59.2 \%$ of all those who were readmitted. Of these patients, $41.2 \%$ were determined to have a condition unrelated to the surgical procedure and instead were readmitted for other clinical reasons. This group was significantly $(p<0.05)$ older, had

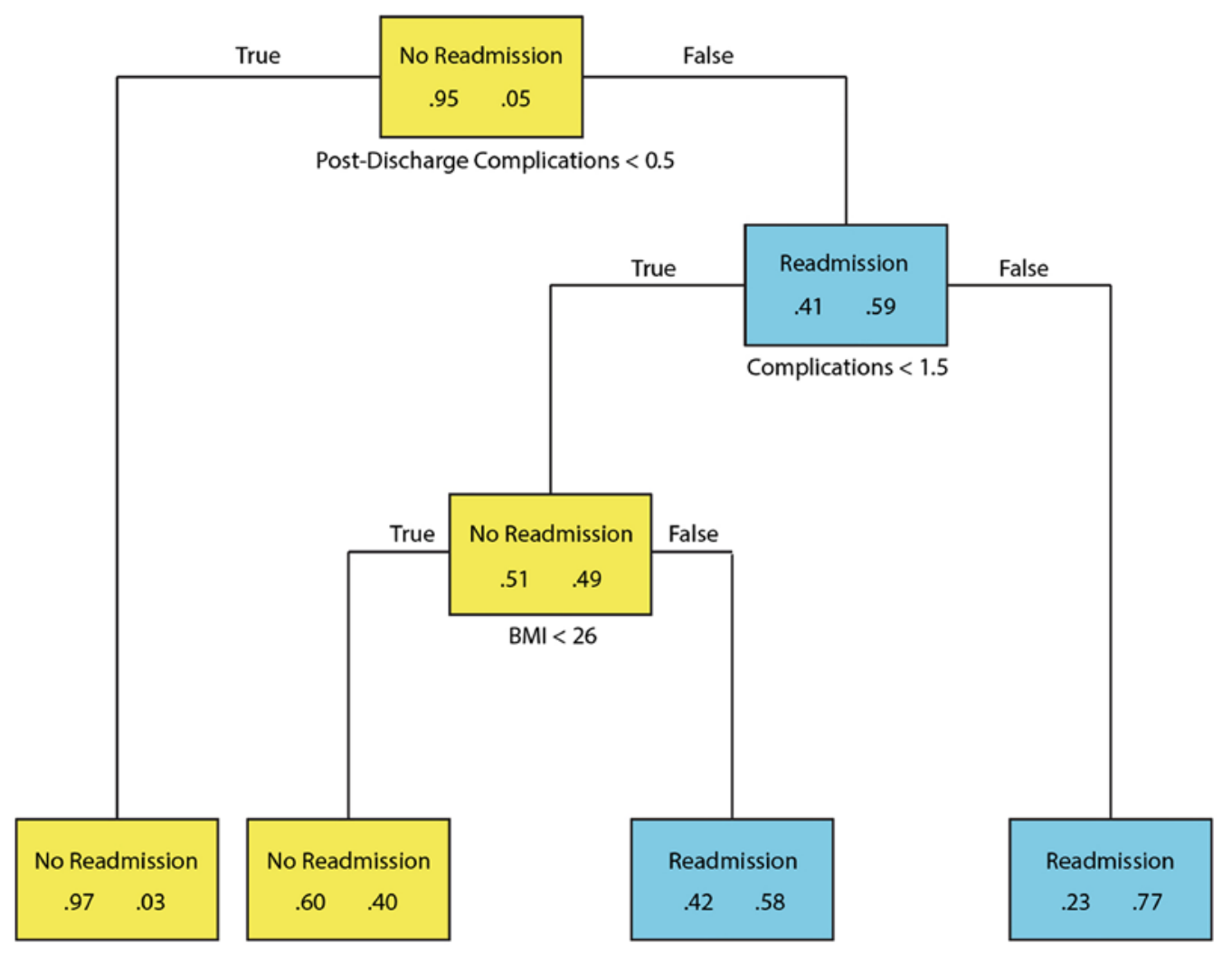

FIG. 1. Decision tree to predict readmission based on patient clinical and demographic factors. Figure is available in color online only. 


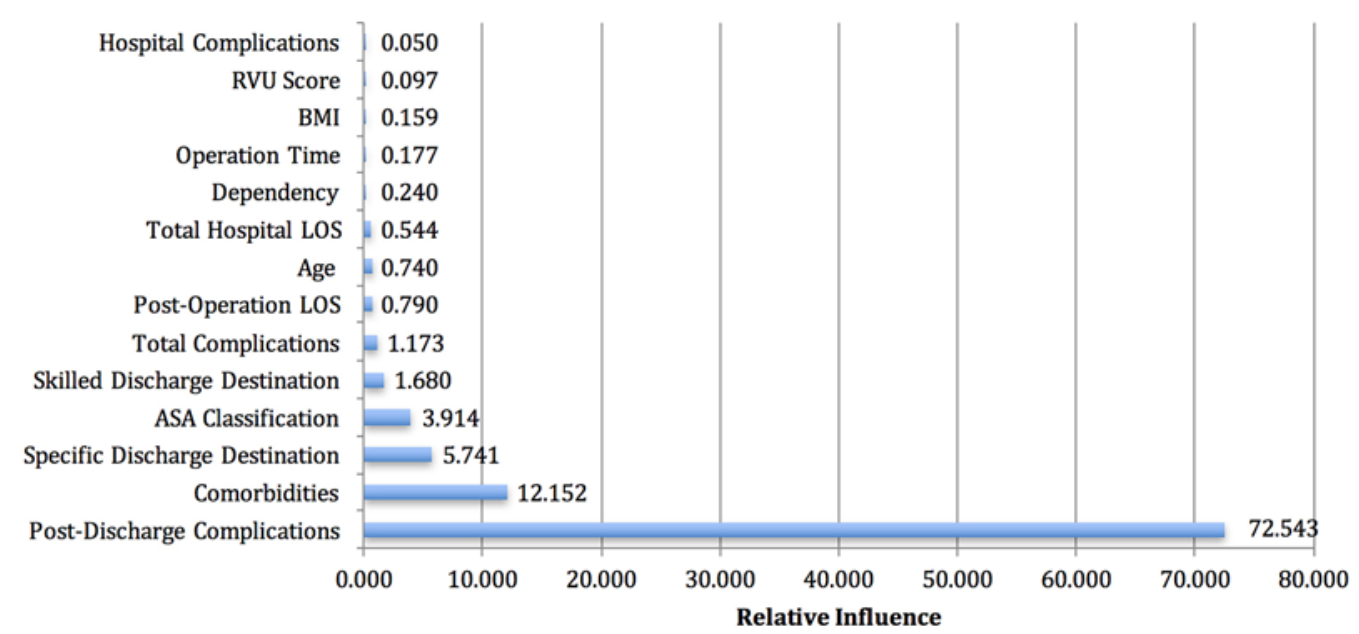

FIG. 2. Variable influence scores in full GBM readmission predictive model. Figure is available in color online only.

a greater number of comorbidities, and had a higher ASA classification than those who were readmitted with conditions attributable to their operation. The remaining $58.7 \%$ had other complications related to the procedure, most commonly "acute postoperative pain," which accounted for $13 \%$ of the other readmissions.

\section{Models Containing All Variables: GBM Learning}

The GBM model to identify readmission was $95.33 \%$ accurate (95\% CI 94.64\%-95.96\%) with an AUC of 0.8059 . The specificity was 0.9808 and the sensitivity was 0.4955 . The most important variable in the model was postdischarge complications, followed by comorbidities, discharge destination, ASA classification, and total number of complications. The relative influence scores of the other variables were less than 1 , signifying that they only minimally impacted the model. Notably, in-hospital complications were the least important factors in identifying
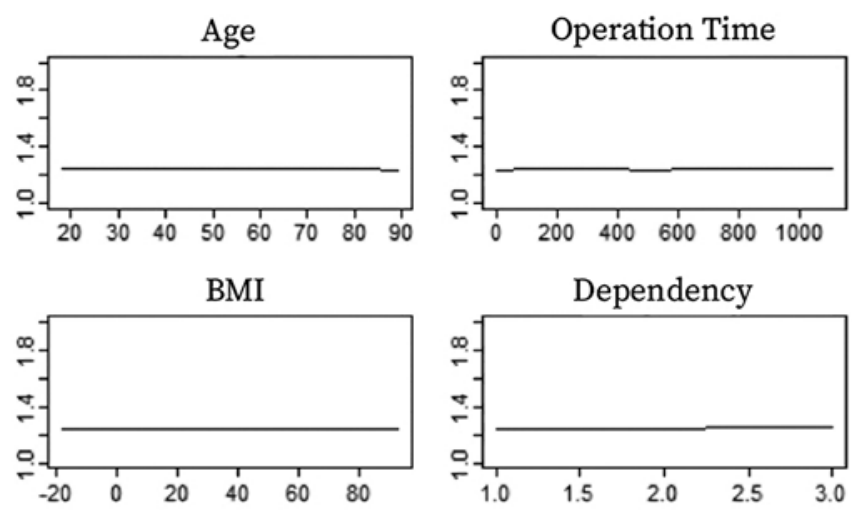

ASA

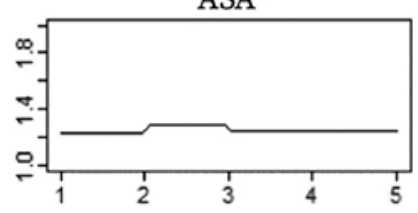

Total Complications

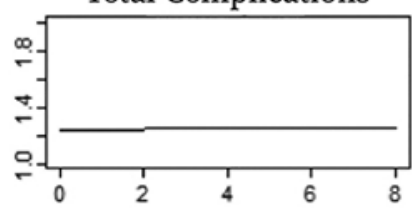

Total Hospital LOS

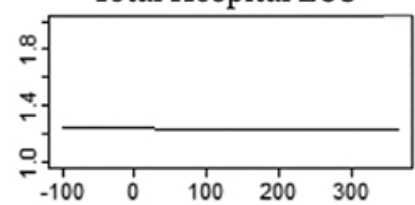

Hospital Complications

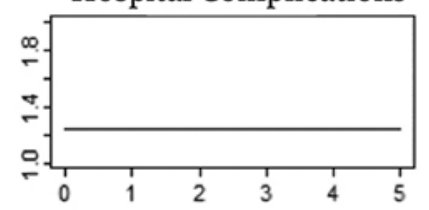

Comorbidities

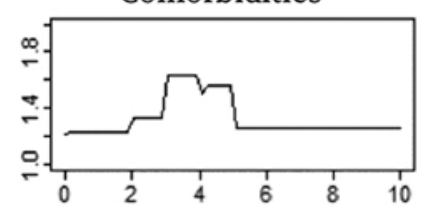

Post-Operative LOS

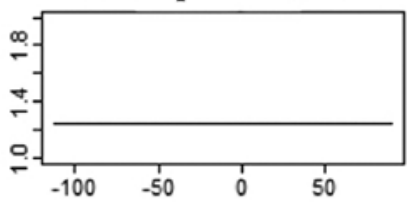

Skilled Discharge Destination

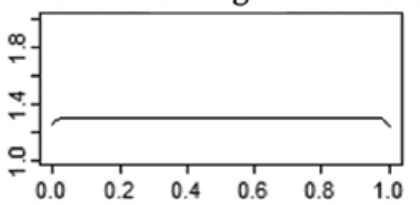

Post-Discharge Complications

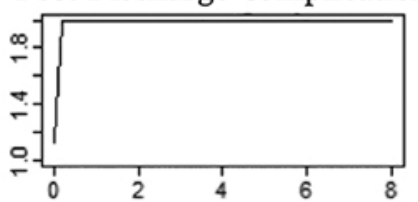

FIG. 3. Partial dependency plots of all variables' marginal effects on readmission. 


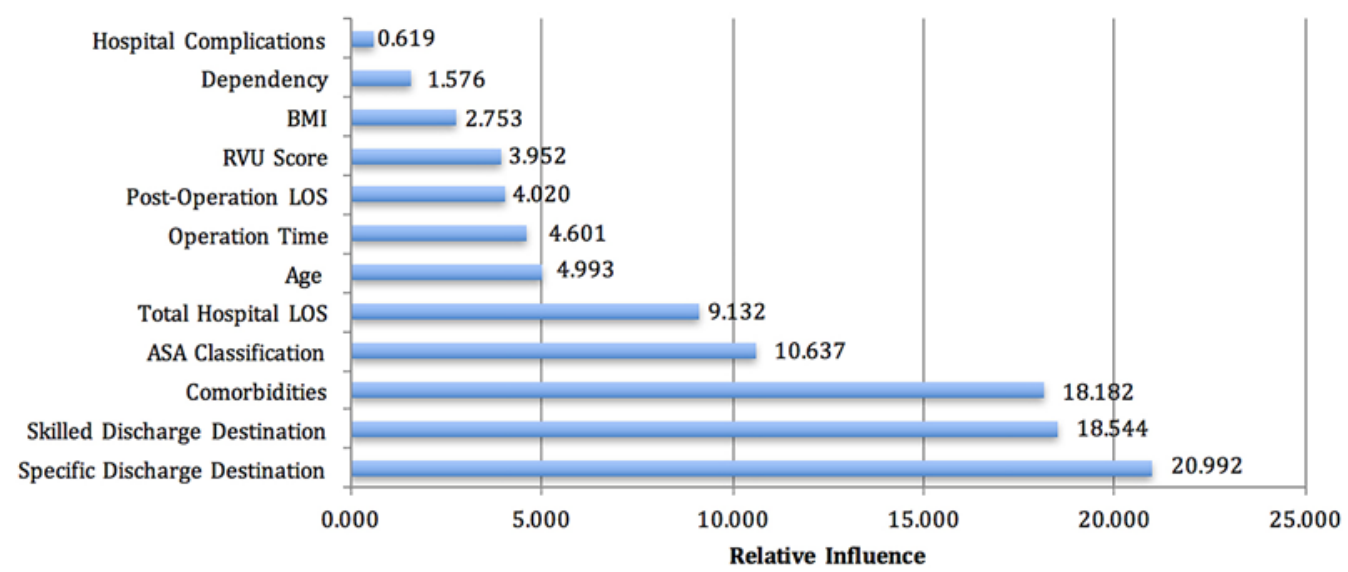

FIG. 4. Variable influence scores in predischarge GBM readmission predictive model. Figure is available in color online only.

readmission (Fig. 2). The partial dependency plots for the model (Fig. 3) similarly showed that the presence of postdischarge complications and the number of comorbidities have the greatest effects on readmission. Interestingly, only patients with three to five comorbidities had a considerably increased readmission risk. Lower and higher comorbidity numbers outside of this range were not associated with more readmissions.

\section{Model Containing Only Predischarge Variables: GBM Learning}

The GBM model to predict readmission with only information known prior to readmission had an accuracy of 79.55\% (95\% CI 78.27\%-80.78\%) and an AUC of 0.6901. The sensitivity of the model was $40.45 \%$ and the specificity was $81.81 \%$. The most important variables in forecasting readmission were discharge destination, comorbidities, ASA classification, and total hospital LOS. The other variables had little effect on the model. As in the other model, the presence of in-hospital complications had the least influence on predicting readmission (Fig. 4).

The partial dependency plots with the predischarge variables (Fig. 5) demonstrated that ASA class, number of comorbidities, and type of discharge destination had the greatest effects on readmission rates. Patients with ASA scores that indicate mild (ASA class 2) or severe (ASA class 3) systemic disease had higher readmission rates than those with no systemic disease or with life-threatening systemic disease. The presence of at least one comorbidity, but especially between three and five comorbidities, increased readmission occurrence. Lastly, discharge to home, a skilled care facility, or separate acute care was associated with less readmission than discharge to rehab, an unskilled facility, or a facility that was previously home.

\section{Discussion}

In this study we identified factors associated with hospital readmission following laminectomy and created a predictive model capable of detecting readmitted patients with the GBM model being $95.33 \%$ accurate with an AUC of 0.8059 , indicating strong discriminative ability. ${ }^{16}$ It was also highly specific, signifying that any negative readmission projection has a high probability of accuracy; $97.04 \%$ of the negative predictions were accurate, higher than the 94.54\% no-readmission rate and indicating potential clinical usefulness.

Overall, the model with all variables identified approximately half of the readmitted patients, and consistent with findings in previous studies, the most significant variable was the number of common surgical postdischarge complications. ${ }^{21,32}$ A little more than half of all patients with postdischarge complications were readmitted, with the probability of readmission increasing to over $80 \%$ only when the number of postdischarge complications was three or greater. Taken together, these data indicate that the model has predictive ability in forecasting readmission if patients are followed after initial discharge and that the presence of postdischarge complications does not guarantee readmission.

The GBM model that utilized only predischarge information was $79.55 \%$ accurate with a sensitivity of $40.5 \%$ and an AUC of 0.6901, indicating fair predictive ability. Though less accurate than the first model, the predischarge GBM model was able to predict approximately $40 \%$ of future readmissions with no information about postdischarge complications. As previous studies have noted, reducing readmission by even a few percentage points would have a considerable impact on the economic burden. ${ }^{32}$

A binary logistic regression including the same variables as the full GBM model yielded a Cox-Snell $\mathrm{R}^{2}$ value of 0.096 and was able to identify $25.3 \%$ of readmissions, which is substantially lower than the $49.6 \%$ identified with GBM. A similar regression model including only the variables in the predischarge GBM model yielded a Cox-Snell $\mathrm{R}^{2}$ value of 0.015 and was able to identify $0 \%$ of readmissions, which again is considerably lower than the $40.5 \%$ identified with GBM. Taken together, these data indicate that the machine learning model was able to predict hospital readmission more accurately than standard regression statistics.

The cause of readmission varied widely among the patient population. Sixty percent of readmission cases had no postdischarge surgical complications recorded in the 

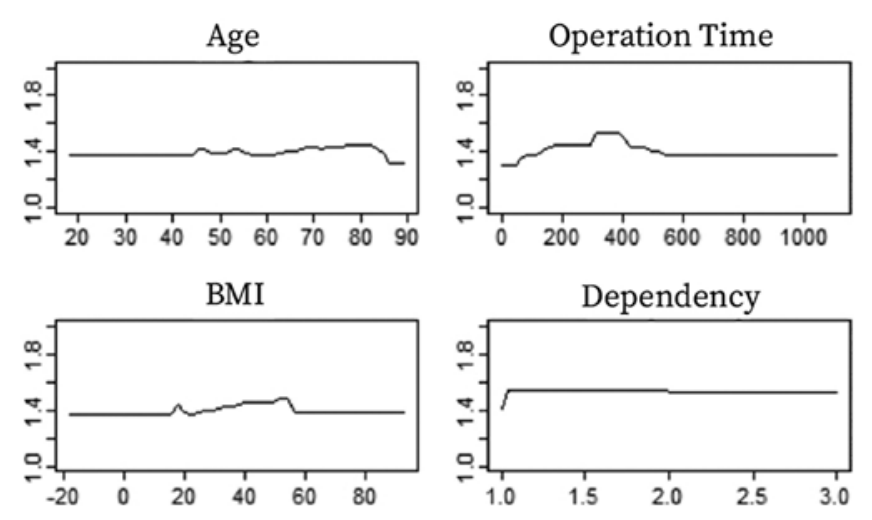

ASA
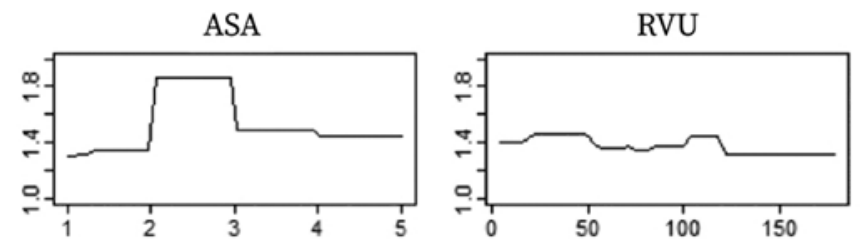

Total Hospital LOS

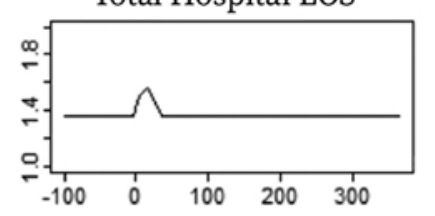

Hospital Complications

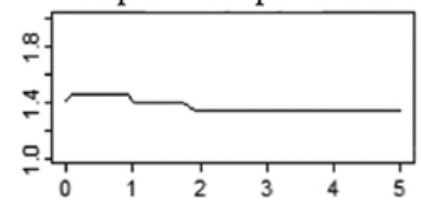

Comorbidities

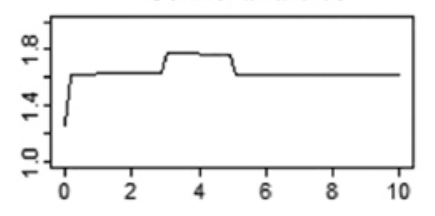

Post-Operative LOS

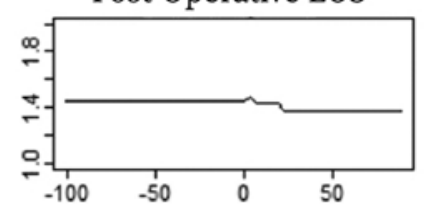

Skilled Discharged Destination

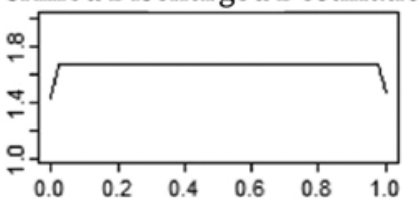

Specific Discharge Destination

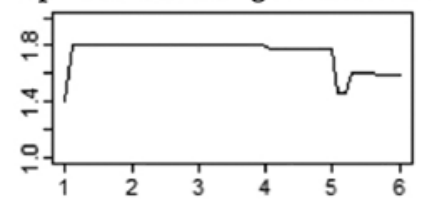

FIG. 5. Partial dependency plots of predischarge variables' marginal effects on readmission.

NSQIP. Among all patients, 24\% were readmitted due to other health conditions unrelated to the laminectomy, and another $36 \%$ had various diagnoses for readmission. However, more than $40 \%$ of the readmitted patients, or just those with postdischarge complications, were identified by the algorithm. Thus, the model was able to identify patient factors that increased readmission risk not related to the common complications and that existed throughout the population. Further research utilizing data with a greater breadth of predictive characteristics is warranted.

The most important variable for predicting readmission a priori was discharge destination. Readmitted patients were significantly more likely to go to a skilled destination after the operation. Compared to those discharged home after surgery, patients who are discharged to professional facilities tend to have worse health overall; this is supported by the fact that comorbidities and ASA classification are the next most important predictors of readmission. Thus, future hospital readmission seems largely linked to health status prior to surgery, which can be used to identify high-risk patients. It is also noteworthy that both models identified in-hospital complications as the least important variable in predicting readmission. This suggests that spine surgeons and their consulting physician services are largely able to effectively manage in-hospital complications without affecting readmission risk.

In general, black box machine learning methods are typically more accurate for numerous applications because they do not make the assumptions that other methods, such as logistic regression, make when analyzing data. ${ }^{9,12,42}$ Further, comparisons of different methodologies in predicting health outcomes have often revealed that black box learning methods outperform more traditional statistical techniques such as regression. ${ }^{33,39}$ Consequently, machine learning methods are becoming increasingly useful and relevant across the healthcare industry and will likely become an important part of risk management, diagnosis, and the management of the everyday practice of medicine going forward.,23 As public health surveillance continues to evolve, the granularity of machine learning models can also improve with higher-quality and more specific patient information, enhancing the predictive power of the models.

One systematic review examined 9 different predictive readmission models that used retrospective US health data and reported an AUC value; of these studies, none had as high an AUC or discriminative power to predict readmission as the model in our investigation. ${ }^{17}$ Other risk indices for readmission, such as the LACE score, had a slightly lower AUC than the predischarge model presented in this study.$^{35}$ Another study compared 14 various machine learning and regression techniques in predicting readmission. The model with the best discriminative power was a black box technique, and its AUC was also slightly lower than the AUC for the GBM predischarge model. ${ }^{14}$

This study has several potential limitations. Most algorithms work best if data are evenly split between the various outcomes and many are not accurate with rare events. ${ }^{36}$ However, readmission data for the most part are imbalanced and have many more cases of those who were not readmitted. This makes readmission difficult to model using traditional machine learning; differentially sampling the cases may result in overfitting. Moreover, GBM models themselves are prone to overfitting the data if not properly tested. ${ }^{20}$ Note, we did employ pruning and used a testing data set in an effort to reduce the impact of overfitting and certify our model. However, future studies must gather more data to validate the algorithm before it can be applied. Once validated, the algorithm can be converted to a readmission risk scoring tool that can be easily utilized in the clinical setting.

\section{Conclusions}

This investigation demonstrated that readmitted pa- 
tients differ from non-readmitted patients in most factors and that readmission can be predicted accurately with only predischarge information. A substantial number of readmissions following laminectomy may not be attributable to the procedure itself, but rather to other patient-level characteristics, including comorbidities and discharge destination. Further, machine learning methods predict readmission more accurately than regression statistics. Machine learning predictive models in the clinical setting can identify patients who are at higher risk for readmission in order to develop more targeted interventions to prevent unnecessary readmission following laminectomy.

\section{References}

1. ACS NSQIP: Data Collection, Analysis, and Reporting. Chicago: American College of Surgeons (https://www.facs. org/quality-programs/acs-nsqip/joinnow/data) [Accessed September 12, 2018]

2. Adogwa O, Elsamadicy AA, Han JL, Karikari IO, Cheng J, Bagley CA: 30-day readmission after spine surgery: an analysis of 1400 consecutive spine surgery patients. Spine (Phila Pa 1976) 42:520-524, 2017

3. Advisory Board: The 2,597 hospitals facing readmissions penalties this year. Daily Briefing. August 4, 2016 (https:// www.advisory.com/daily-briefing/2016/08/04/hospitalsfacing-readmission-penalties) [Accessed September 12, 2018]

4. Agency for Healthcare Research and Quality: Preventing avoidable readmissions. AHRQ.gov (https://www.ahrq.gov/ professionals/quality-patient-safety/patient-safety-resources/ resources/impptdis/index.html) [Accessed September 12, 2018]

5. Ahmad SA, Edwards MJ, Sutton JM, Grewal SS, Hanseman DJ, Maithel SK, et al: Factors influencing readmission after pancreaticoduodenectomy: a multi-institutional study of 1302 patients. Ann Surg 256:529-537, 2012

6. Ansari SF, Yan H, Zou J, Worth RM, Barbaro NM: Hospital length of stay and readmission rate for neurosurgical patients. Neurosurgery 82:173-181, 2018

7. Baig MM, Hosseini HG, Lindén M: Machine learning-based clinical decision support system for early diagnosis from real-time physiological data, in 2016 IEEE Region 10 Conference (TENCON). New York: IEEE, 2016, pp 2943-2946

8. Bernatz JT, Anderson PA: Thirty-day readmission rates in spine surgery: systematic review and meta-analysis. Neurosurg Focus 39(4):E7, 2015

9. Breiman L: Statistical modeling: The two cultures (with comments and a rejoinder by the author). Stat Sci 16:199-231, 2001

10. Chawla NV, Bowyer KW, Hall LO, Kegelmeyer WP: SMOTE: synthetic minority over-sampling technique. J Artif Intell Res 16:321-357, 2002

11. Corrigan JM, Martin JB: Identification of factors associated with hospital readmission and development of a predictive model. Health Serv Res 27:81-101, 1992

12. Dreiseitl S, Ohno-Machado L: Logistic regression and artificial neural network classification models: a methodology review. J Biomed Inform 35:352-359, 2002

13. Friedman JH: Greedy function approximation: a gradient boosting machine. Ann Stat 29:1189-1232, 2001

14. Futoma J, Morris J, Lucas J: A comparison of models for predicting early hospital readmissions. J Biomed Inform 56:229-238, 2015

15. Hines AL, Barrett ML, Jiang HJ, Steiner CA: Conditions With the Largest Number of Adult Hospital Readmissions by Payer, 2011. Statistical Brief \#172. Rockville, MD: Agency for Health Research and Quality, 2006 (https://www.hcup-us.ahrq.gov/reports/statbriefs/sb172-
Conditions-Readmissions-Payer.jsp) [Accessed September 12, 2018]

16. Hosmer DW, Lemeshow S: Applied Logistic Regression, ed 2. New York: John Wiley \& Sons, 2000

17. Kansagara D, Englander H, Salanitro A, Kagen D, Theobald C, Freeman M, et al: Risk prediction models for hospital readmission: a systematic review. JAMA 306:1688-1698, 2011

18. Kassin MT, Owen RM, Perez SD, Leeds I, Cox JC, Schnier $\mathrm{K}$, et al: Risk factors for 30-day hospital readmission among general surgery patients. J Am Coll Surg 215:322-330, 2012

19. Lavenberg JG, Leas B, Umscheid CA, Williams K, Goldmann DR, Kripalani S: Assessing preventability in the quest to reduce hospital readmissions. J Hosp Med 9:598-603, 2014

20. Lawrence R, Bunn A, Powell S, Zambon M: Classification of remotely sensed imagery using stochastic gradient boosting as a refinement of classification tree analysis. Remote Sens Environ 90:331-336, 2004

21. Lawson EH, Hall BL, Louie R, Ettner SL, Zingmond DS, Han L, et al: Association between occurrence of a postoperative complication and readmission: implications for quality improvement and cost savings. Ann Surg 258:10-18, 2013

22. Ludke RL, Booth BM, Lewis-Beck JA: Relationship between early readmission and hospital quality of care indicators. Inquiry 30:95-103, 1993

23. Luo G: PredicT-ML: a tool for automating machine learning model building with big clinical data. Health Inf Sci Syst 4:5, 2016

24. McCormack RA, Hunter T, Ramos N, Michels R, Hutzler L, Bosco JA: An analysis of causes of readmission after spine surgery. Spine (Phila Pa 1976) 37:1260-1266, 2012

25. McIlvennan CK, Eapen ZJ, Allen LA: Hospital readmissions reduction program. Circulation 131:1796-1803, 2015

26. Natekin A, Knoll A: Gradient boosting machines, a tutorial. Front Neurorobot 7:21, 2013

27. Njeim M, Chiha M, Whitehouse S, Baker-Genaw K: Systembased approach to educating internal medicine residents on preventable hospital readmissions. J Grad Med Educ 4:505-509, 2012

28. Osman IM, Godden DJ, Friend JA, Legge JS, Douglas JG: Quality of life and hospital re-admission in patients with chronic obstructive pulmonary disease. Thorax 52:67-71, 1997

29. Pollock K: Spine surgery coding made simple. Industry News. September 1, 2013 (https://www.aapc.com/ blog/25658-procedure-coding-made-simple/) [Accessed September 12, 2018]

30. Rodríguez-Artalejo F, Guallar-Castillón P, Pascual CR, Otero $\mathrm{CM}$, Montes AO, García AN, et al: Health-related quality of life as a predictor of hospital readmission and death among patients with heart failure. Arch Intern Med 165:1274-1279, 2005

31. Saleh A, Thirukumaran C, Mesfin A, Molinari RW: Complications and readmission after lumbar spine surgery in elderly patients: an analysis of 2,320 patients. Spine J 17:1106-1112, 2017

32. Sweeney JF: Postoperative complications and hospital readmissions in surgical patients: an important association. Ann Surg 258:19-20, 2013

33. Thottakkara P, Ozrazgat-Baslanti T, Hupf BB, Rashidi P, Pardalos P, Momcilovic P, et al: Application of machine learning techniques to high-dimensional clinical data to forecast postoperative complications. PLoS One 11:e0155705, 2016

34. Tsai TC, Joynt KE, Orav EJ, Gawande AA, Jha AK: Variation in surgical-readmission rates and quality of hospital care. N Engl J Med 369:1134-1142, 2013

35. van Walraven C, Dhalla IA, Bell C, Etchells E, Stiell IG, Zarnke K, et al: Derivation and validation of an index to predict early death or unplanned readmission after discharge from hospital to the community. CMAJ 182:551-557, 2010 
36. Vilalta R, Ma S: Predicting rare events in temporal domains, in Proceedings of the 2nd IEEE International Conference on Data Mining (ICDM '02). New York: IEEE, 2002, pp 474-481

37. Wan H, Zhang L, Witz S, Musselman KJ, Yi F, Mullen CJ, et al: A literature review of preventable hospital readmissions: preceding the Readmissions Reduction Act. IIE Trans Healthc Syst Eng 6:193-211, 2016

38. Weiss AJ, Elixhauser A, Steiner C: Readmissions to U.S. Hospitals by Procedure, 2010: Statistical Brief \#154. Rockville, MD: Agency for Health Research and Quality, 2006 (https://www.hcup-us.ahrq.gov/reports/statbriefs/sb154. pdf) [Accessed September 12, 2018]

39. Westreich D, Lessler J, Funk MJ: Propensity score estimation: neural networks, support vector machines, decision trees (CART), and meta-classifiers as alternatives to logistic regression. J Clin Epidemiol 63:826-833, 2010

40. Whitman E: Hospitals face record penalties as CMS expands criteria for readmissions fines. Modern Healthcare. August 3, 2016 (http://www.modernhealthcare.com/article/20160803/ NEWS/160809964) [Accessed September 12, 2018]

41. Witten IH, Frank E, Hall MA, Pal CJ: Data Mining: Practical Machine Learning Tools and Techniques. Burlington, MA: Morgan Kaufmann, 2011
42. Yang CC, Veltri P: Intelligent healthcare informatics in big data era. Artif Intell Med 65:75-77, 2015

\section{Disclosures}

Dr. Eltorai receives royalties from Lippincott Williams \& Wilkins and Springer.

\section{Author Contributions}

Conception and design: Daniels, Kalagara, Eltorai. Analysis and interpretation of data: Kalagara. Drafting the article: Kalagara, Eltorai. Critically revising the article: all authors. Reviewed submitted version of manuscript: all authors. Statistical analysis: Kalagara, Durand. Administrative/technical/material support: Daniels, Eltorai. Study supervision: all authors.

\section{Correspondence}

Alan H. Daniels: Warren Alpert Medical School of Brown University, Providence, RI. alan_daniels@brown.edu. 